\title{
Bicarbonate for microalgae cultivation: a case study in a chlorophyte, Tetradesmus wisconsinensis isolated from a Norwegian lake
}

\author{
Ikumi Umetani ${ }^{1,2}$ (D) Eshetu Janka ${ }^{1} \cdot$ Michal Sposób $^{1,2} \cdot$ Chris J. Hulatt $^{3} \cdot$ Synne Kleiven $^{4} \cdot$ Rune Bakke $^{1}$
}

Received: 14 August 2020 / Revised and accepted: 12 February 2021 / Published online: 26 March 2021

(C) The Author(s) 2021

\begin{abstract}
Bicarbonate was evaluated as an alternative carbon source for a green microalga, Tetradesmus wisconsinensis, isolated from Lake Norsjø in Norway. Photosynthesis, growth, and lipid production were studied using four inorganic carbon regimes: (1) aeration only, (2) $20 \mathrm{mM} \mathrm{NaHCO}_{3}$, (3) $5 \%$ (v/v) $\mathrm{CO}_{2}$ gas, and (4) combination of $20 \mathrm{mM} \mathrm{NaHCO}_{3}$ and $5 \% \mathrm{CO}_{2}$. Variable chlorophyll $a$ fluorescence analysis revealed that the bicarbonate treatment supported effective photosynthesis, while the $\mathrm{CO}_{2}$ treatment led to inefficient photosynthetic activity with a PSII maximum quantum yield as low as 0.31 . Conversely, bicarbonate and $\mathrm{CO}_{2}$ treatments gave similar biomass and fatty acid production. The maximum growth rate, the final cell dry weight, and total fatty acids under the bicarbonate-only treatment were $0.33( \pm 0.06)$ day $^{-1}, 673( \pm 124) \mathrm{mg} \mathrm{L}^{-1}$ and $75( \pm 5) \mathrm{mg} \mathrm{g}^{-1}$ dry biomass, respectively. The most abundant fatty acid components were $\alpha$-linolenic acid and polyunsaturated fatty acids constituting $69 \%$ of the total fatty acids. The fatty acid profile eventuated in unsuitable biodiesel fuel properties such as high degree of unsaturation and low cetane number; however, it would be relevant for food and feed applications. We concluded that bicarbonate could give healthy growth and comparative product yields as $\mathrm{CO}_{2}$.
\end{abstract}

Keywords Tetradesmus $\cdot$ Inorganic carbon source $\cdot$ Chlorophyll $a$ fluorescence $\cdot$ Biomass $\cdot$ Fatty acids $\cdot$ Biodiesel fuel properties

\section{Introduction}

Microalgae are promising sources of valuable pharmaceuticals and alternative green energy in near-future industries (Georgianna and Mayfield 2012; Borowitzka 2013; Wells et al. 2017; Barsanti and Gualtieri 2018). There has been substantial interest in using microalgae as third-generation feedstock for the biofuel industry (Wigmosta et al. 2011; Georgianna and Mayfield 2012). Microalgae have considerable advantages over first- and second-generation feedstocks

Rune Bakke passed away December 15, 2020

Ikumi Umetani

ikumi.umetani@nibio.no

1 Department of Process, Energy and Environmental Technology, University of South-Eastern Norway, 3918 Porsgrunn, Norway

2 Division of Environment and Natural Resources, Norwegian Institute of Bioeconomy Research, 1431 Ås, Norway

3 Faculty of Biosciences and Aquaculture, Nord University, 8049 Bodø, Norway

4 Department of Natural Sciences and Environmental Health, University of South-Eastern Norway, 3800 Bø, Norway not only because they are able to produce higher yields of biomass and lipids but also because their cultivation can take place in land areas where there is lower competition with food crops (Hu et al. 2008; Georgianna and Mayfield 2012; Slade and Bauen 2013). Further, microalgae are favourable for the concept of biorefinery systems, where their biomass can be exploited for several different commodities in addition to biofuel (Posada et al. 2016). Recent research focus for microalgae production has been the integration of carbon capture and/or wastewater treatment technology for sustainable and costefficient use of $\mathrm{CO}_{2}$, nutrient, and water (Georgianna and Mayfield 2012; Meier et al. 2015; Gonçalves et al. 2017; Mondal et al. 2017; Singh and Dhar 2019).

The majority of microalgae are photoautotrophic, i.e. they conduct photosynthesis and utilize inorganic carbon for their metabolism. Microalgae must obtain inorganic carbon from the surrounding water where speciation of dissolved inorganic carbon is highly dependent on the $\mathrm{pH}$, and their growth and physiology can be influenced by the availability of $\mathrm{CO}_{2}$ and $\mathrm{HCO}_{3}{ }^{-}$(Thielmann et al. 1990; Chen et al. 2016). Most species of microalgae, including the members of Chlorophyta, possess carbon concentrating mechanisms (CCMs), although exceptions have been found so far in nearly all of freshwater chrysophytes and synurophytes (Heterokontophyta) (Raven 
2010; Raven and Beardall 2014). CCMs involve reversible dehydration of $\mathrm{HCO}_{3}{ }^{-}$to $\mathrm{CO}_{2}$ for extracellular and intracellular cross-membrane transport and storage of inorganic carbon. This mechanism provides ribulose-1,5-biphosphate carboxylase/oxygenase (RuBisCo) sufficient concentration of $\mathrm{CO}_{2}$ to reduce the counterproductive oxygenase activity (Giordano et al. 2005; Raven 2010).

Commercial scale production of microalgae either in open ponds or closed photobioreactor systems requires supplementation of inorganic carbon to maintain high yields. The common practice is to add $\mathrm{CO}_{2}$-enriched gas, although the efficiency of $\mathrm{CO}_{2}$ supplementation seems to be scarcely considered. Regardless of the optimum amount of $\mathrm{CO}_{2}$ added to supplement microalgae growth, the outgassing of excess $\mathrm{CO}_{2}$ is an unavoidable loss. Only a small fraction of $\mathrm{CO}_{2}$ sparged into the growth media will be utilized by the microalgae due to incomplete mass transfer of gas into liquid (Scherholz and Curtis 2013; Wang and Curtis 2016). The excess $\mathrm{CO}_{2}$ emitted from microalgae production system into the atmosphere reduces the efficiency of microalgae carbon capture. The loss of $\mathrm{CO}_{2}$ can be minimized by controlling $\mathrm{pH}$ using a $\mathrm{pH}$-stat system (Moheimani 2013). Another approach is using bicarbonate, which can be dissolved in the growth medium as a complete inorganic carbon source or a partial substitution of the gaseous $\mathrm{CO}_{2}$ in microalgae culture. Inorganic carbon supplementation in the form of $\mathrm{HCO}_{3}{ }^{-}$has been proved to enhance lipid accumulation as well as to sustain healthy growth in diatoms and green microalgae (Gardner et al. 2012; White et al. 2013). Bicarbonate is also recommended as a feasible and superior carbon form to $\mathrm{CO}_{2}$ for operation of carbon capture combined with microalgae production (Chi et al. 2011).

The performance of microalgae in production systems is generally estimated by measuring increases in cell concentrations, but a further insight can be obtainable using direct measurements of photosynthetic activity (Malapascua et al. 2014). Variable chlorophyll fluorescence is widely used as a sensitive and reliable tool for measuring photosynthesis efficiency particularly of PSII (Maxwell and Johnson 2000; Strasser et al. 2000; Baker and Oxborough 2004; Baker and Rosenqvist 2004; Baker 2008; Stirbet and Govindjee 2011). Upon illumination of a dark-adapted photosynthetic organism, a rise in chlorophyll $a$ fluorescence occurs. The fluorescence rise shows typical kinetics, O-J-I-P, where $\mathrm{O}$ is the origin indicating minimal level, $\mathrm{J}$ and $\mathrm{I}$ are intermediate levels, and $\mathrm{P}$ is maximum level (Lazar 1999; Baker 2008; Murchie and Lawson 2013). The OJIP transients correlate with the rates of photochemistry at PSII reaction centre (RC) including the oxygen-evolving complex, and the flow of electron from PSII $\mathrm{RC}$ into the electron transport chain that connected to the electron acceptor side of PSI (Strasser et al. 1995). The O-J rise explains the efficiency of the PSII photochemistry leading to the reduction of the primary electron acceptor $\mathrm{Q}_{\mathrm{A}}$ at the
PSII. The J level relates to the different states of the plastoquinone (PQ) pool. The $\mathrm{P}$ level indicates the maximum capacity for reducing all PQ molecules to $\mathrm{PQH}_{2}$, which depends on the efficiency at the electron acceptor side of PSI (Strasser et al. 1995; Stirbet and Govindjee 2011). Therefore, the analysis of the OJIP transient allows us to obtain detailed information about structure and function of PSII and, further, to understand the overall status of the photosynthetic activity of sample organisms (Strasser et al. 2004).

The objective of this study was to investigate the effects of inorganic carbon sources on biomass and lipid production of microalgae, focusing particularly on their photosynthesis activities in response to the inorganic carbon regimes. A chlorophyte, Tetradesmus wisconsinensis, isolated from a Norwegian lake was used as a model organism. Tetradesmus wisconsinensis belongs to the family Scenedesmaceae and is one of the Tetradesmus species recently transferred from the genus Acutodesmus (Hegewald et al. 2013; Wynne and Hallan 2015). Previously, several species of Tetradesmus/ Acutodesmus have been reported as favourable candidates for biodiesel production because of their high lipid contents and suitable fatty acid profiles (Ferrigo et al. 2015; Ismagulova et al. 2018). However, limited information is available for T. wisconsinensis (Lang et al. 2011). Therefore, another aim of this study was to evaluate fatty acid profile of our $T$. wisconsinensis strain for biotechnology applications.

\section{Materials and methods}

\section{Microalgae}

Tetradesmus wisconsinensis strain $\mathrm{H} 1$ was isolated from a field water sample collected from Lake Norsjø in Telemark, Norway $\left(59^{\circ} 12^{\prime} \mathrm{N}, 9^{\circ} 32^{\prime} \mathrm{E}\right)$ and was grown to establish a monoculture. Species was identified based on 18S rDNA phylogeny and morphology. PCR was conducted using primer pairs, INT-4F/ITS4 (White et al. 1990; Hoshina et al. 2005; Hoshina 2014), and the amplified fragment was sequenced using ABI 3130xl DNA Sequencer (Applied Biosystems, USA). The sample sequence showed 96-98\% blast similarity to the members of Tetradesmus, and species was determined by their characteristic "bundle-like" four-celled coenobium (Online Resource Fig. 1), which distinguishes T. wisconsinensis from other Tetradesmus species morphologically (Smith 1916; An et al. 1999). The sequence data is available in GenBank with the accession number MT968755.

\section{Experimental conditions}

Inoculation culture was grown without aeration for 18 days. The experiment was performed as batch cultures in $1-\mathrm{L}$ Erlenmeyer flask (600 mL medium) and the duration was 14 
days. Four inorganic carbon regimes were tested, including (1) no additional inorganic carbon source other than by aeration with air, (2) addition of $20 \mathrm{mM} \mathrm{NaHCO}_{3}$ at the start of the experiment, (3) continuous supply of $5 \% \mathrm{v} / \mathrm{v} \mathrm{CO}_{2}$ in air, and (4) addition of $20 \mathrm{mM} \mathrm{NaHCO}_{3}$ at the start of the experiment and continuous supply of $5 \% \mathrm{v} / \mathrm{v} \mathrm{CO}_{2}$ in air. The concentration of $\mathrm{NaHCO}_{3}$ was chosen based on our previous study (Janka et al. 2019). Growth medium used for the experiment was Bold's Basal Medium (BBM) (Bischoff and Bold 1963), in which $\mathrm{NaNO}_{3}, \mathrm{MoO}_{3}$, and $\mathrm{Co}\left(\mathrm{NO}_{3}\right)_{2} \cdot 6 \mathrm{H}_{2} \mathrm{O}$ were replaced with $\mathrm{KNO}_{3}, \mathrm{Na}_{2} \mathrm{MoO}_{4} \cdot 2 \mathrm{H}_{2} \mathrm{O}$, and $\mathrm{CoCl}_{2} \cdot 6 \mathrm{H}_{2} \mathrm{O}$, respectively. The initial $\mathrm{pH}$ of the medium was 6.1 for regimes 1 and 3 , and 6.7 for regimes 2 and 4 after the addition of $\mathrm{NaHCO}_{3}$. The samples were held at $19{ }^{\circ} \mathrm{C}$ in a fume hood and were exposed to a $16 / 8 \mathrm{~h} \mathrm{light/dark}$ cycle. The average light intensity at the surface of the flasks was $70 \mu \mathrm{mol}$ photons $\mathrm{m}^{-2} \mathrm{~s}^{-1}$, which is provided by white LED tube battens (Civilight, Eschborn, Germany). All samples received continuous aeration $(250 \mathrm{~L}$ $\left.\mathrm{h}^{-1}\right)$ with sterilized air through syringe filters $(0.25 \mu \mathrm{m}$ cellulose acetate membrane, VWR, USA) using aeration pumps (Eheim, Germany).

\section{Growth and biomass production}

Optical density (OD) at $740 \mathrm{~nm}$ was measured six times during the experiment (days $2,4,6,8,10$, and 14) using a spectrophotometer (Lambda 25, UV/VIS Spectrophotometer, Perkin Elmer, USA). The specific growth rate $(\mu)$ was calculated using the following equation, where $N_{1}$ and $N_{2}$ are the biomass concentrations (OD) at times (days) $t_{1}$ and $t_{2}$ during exponential growth phase (Mayers et al. 2014):

$\mu=\left(\ln N_{2}-\ln N_{1}\right) / t_{2}-t_{1}$

The dry weight was measured by filtering $20 \mathrm{~mL}$ samples through $47 \mathrm{~mm} \mathrm{GF} / \mathrm{C}$ glass fibre filters (Whatman, U.K.), and then drying in an oven at $150^{\circ} \mathrm{C}$ for $20 \mathrm{~h}$.

\section{Nitrate and phosphate and pH in media}

The samples for nitrate and phosphate measurements were filtered through $0.25-\mu \mathrm{m}$ pore-size syringe filters (cellulose acetate membrane, VWR) and were stored in the fridge before the analysis. Analysis was performed by ion chromatography (Dionex ICS-5000, USA) using the method described previously (Sposob et al. 2017). Sample separation and elution was performed using an IonPac AS11-HC 2-mm analytical column with potassium hydroxide $(\mathrm{KOH})$ as eluent. The $\mathrm{pH}$ was measured in $15 \mathrm{~mL}$ collected samples using an inoLab pH 7110 pH meter (WTW, Germany).

\section{Chlorophyll fluorescence}

The measurement of chlorophyll fluorescence (photosynthetic parameters) was carried out five times (days 2, 4, 6, 8, and 14) during the experiment using a handheld fluorimeter AquaPenC AP-C 100 (Photon Systems Instruments, Czech Republic). The excitation wavelength was at $455 \mathrm{~nm}$ with a blue LED emitter and the measuring light of PAR values was up to $3000 \mu \mathrm{mol}$ photons $\mathrm{m}^{-2} \mathrm{~s}^{-1}$. Before the measurement, a 4 $\mathrm{mL}$ sample was dark adapted for $10 \mathrm{~min}$ in a cuvette. The dark adaptation time was chosen prior to the experiment by measuring the time giving the highest QY values in three samples of $T$. wisconsinensis cultures grown with aeration. The samples were diluted accordingly with the medium when the OD measurement exceeded 0.5 in order to keep fluorescence values within the measurable range. The FluorPen software (Photon Systems Instruments) was used to conduct JIP-test, which is an analysis of the OJIP fluorescence transient curve based on PSII energy flux model (Strasser et al. 2000). The JIP parameters are calculated using fluorescent signals extracted from the fast chlorophyll $a$ fluorescence transient for characterizing photosynthetic activities at given physiological states of the test organisms (Online Resource Table S1) (Strasser et al. 2000, 2004).

\section{Fatty acids}

Fatty acid analysis was conducted as described in Hulatt et al. (2017). Samples were centrifuged at $5000 \mathrm{xg}$ for $10 \mathrm{~min}$ and the pellets were freeze-dried. Six milligram of the lyophilized samples was weighed using a precision balance (MX5, Mettler-Toledo), and $4.0 \mathrm{~mL}$ of chloroform/methanol solution $(2: 2.5 \mathrm{v} / \mathrm{v})$ spiked with internal standard (Tripentadecanoin, C15:0 Triacylglycerol, Sigma-Aldrich) was added. The cells were disrupted by a bead mill (MagNA lyser, Roche, $0.1 \mathrm{~mm}$ glass beads) and a sonication bath. They were then treated with $2.5-\mathrm{mL}$ aqueous Tris buffer $\left(6 \mathrm{~g} \mathrm{~L}^{-1}\right.$ Tris, $58 \mathrm{~g} \mathrm{~L}^{-1}$ $\mathrm{NaCl}, \mathrm{pH} 7.5)$, vortexed for $10 \mathrm{~s}$, and centrifuged at 1500 $\mathrm{x}$. Total lipids were recovered by drying under a stream of nitrogen to remove the chloroform phase. The extracted lipids were incubated in acidic methanol $\left(3.0 \mathrm{~mL} 5 \% \mathrm{H}_{2} \mathrm{SO}_{4}\right.$ in methanol) at $70{ }^{\circ} \mathrm{C}$ for $3 \mathrm{~h}$ for derivatization of the fatty acyl chains to fatty acid methyl-esters (FAMEs). The FAMEs were recovered by mixing with $3.0 \mathrm{~mL}$ of hexane for $30 \mathrm{~min}$. Quantification of FAMEs was conducted by gas chromatography (GC) with a flame ionization detector (SCION 436, Bruker, USA), which was fitted with an Agilent CP-Wax 52 $\mathrm{CB}$ column. Individual FAMEs were identified and quantitated using a Supelco 37-component standard for common fatty acids and additional standards for unusual unsaturated fatty acids (Larodan Fine Chemicals, Sweden). Recovery and efficiency of transesterification were average $97.2( \pm 7.5) \%$. 


\section{Biodiesel fuel properties}

The biodiesel properties used to evaluate biodiesel quality were the saponification value, the iodine value, the cetane number, the degree of unsaturation, the long-chain saturation factor, and the cold filter plugging point proposed by Ramos et al. (2009). The cetane number $(\mathrm{CN})$ is predicted by the chain length expressed by the saponification value (SV) and the degree of unsaturation expressed by the iodine value (IV) of the FAMEs using the following equations, where $D$ is the number of double bonds, $M$ is the molecular weight, and $N$ is the percentage of each FAME (Krisnangkura 1986):

$$
\begin{aligned}
& S V=\Sigma(560 \times N) / M \\
& I V=\Sigma(254 \times D \times N) / M \\
& C N=46.3+(5458 / S V)-(0.225 \times I V)
\end{aligned}
$$

The degree of unsaturation (DU) is calculated by the weight percentage of monounsaturated fatty acids (MUFA) and polyunsaturated fatty acids (PUFA) present in the FAME (Ramos et al. 2009):

$D U=M U F A+(2 \times P U F A)$

The cold filter plugging point (CFPP) is calculated from the long-chain saturation factor (LCSF) considering the impact of the composition of saturated fatty acids (weight percentages) and their chain lengths (Ramos et al. 2009):

$$
\begin{aligned}
L C S F= & (0.1 \times C 16: 0)+(0.5 \times C 18: 0) \\
& +(1 \times C 20: 0)+(1.5 \times C 22: 0) \\
& +(2 \times C 24: 0) \\
C F P P= & (3.1417 \times L C S F)-16.477
\end{aligned}
$$

\section{Data analysis}

Principal component analysis (PCA) was applied to the fluorescence data collected for the JIP-test (Online Resource Table S1) and factor map of the PCA result was made using FactoMineR package (Lê et al. 2008) with R software (R version 4.0.3).

\section{Results}

\section{Growth rate and biomass production}

Growth curves based on the OD measurements showed similar increase in cell density, especially between the bicarbonate and $\mathrm{CO}_{2}$-only regimes (Fig. 1a). Dry cell weights in the sample cultures at the end of the experiment were similar between the inorganic carbon regimes (Fig. 1b). The biomass obtained was $673( \pm 124), 658( \pm 117)$, and $585( \pm 219) \mathrm{mg}$ $\mathrm{L}^{-1}$, under bicarbonate, $\mathrm{CO}_{2}$, and mixed carbon supplementations, respectively (Fig. 1b). Analysis of growth rate revealed variations among the treatments. Bicarbonate supplementation gave relatively stable growth rates ranging from $0.20( \pm$ $0.01)$ to $0.33( \pm 0.06)$ day $^{-1}$ (Table 1). The growth rates under $\mathrm{CO}_{2}$ supplementation were recorded $0.12( \pm 0.03)$ day $^{-1}$ at day 2 and $0.47( \pm 0.11)$ day $^{-1}$ at day 4 , which were the lowest and highest of the record among all regimes, respectively (Table 1). The growth rate under mixed carbon regime was lowered to 0.17 ( \pm 0.09$)$ day $^{-1}$ between day 6 to 8 , but it increased after day 8 (Table 1).

\section{Nutrient uptake and pH}

Nitrate was substantially depleted in all culture media at the end of the experiment (Fig. 2a), while dissolved phosphate was in excess throughout the experiment (Fig. 2b).

The $\mathrm{pH}$ of the $\mathrm{CO}_{2}$-supplemented medium dropped to 5.2 at day 2. It remained below 6.0 until day 10 , but it increased to 6.5 at day 14 . The medium with the bicarbonate supplementation showed a steady increase from $\mathrm{pH} 7.9$ to 10.1 (Fig. 3). A noticeable increase of $\mathrm{pH}$ was observed for the mixed carbon medium at day 8 , although the $\mathrm{pH}$ did not exceed those of the bicarbonate-only supplied medium (Fig. 3 ). The medium that received only aeration had stable $\mathrm{pH}$ around 7.5 before increasing remarkably from day 10 .

\section{Photosynthesis}

The analysis of OJIP fluorescence transient of $T$. wisconsinensis under the different inorganic carbon regimes was performed for the five sampling days during their cultivation (days 2, 4, 6, 8, and 14) (Online Resource Fig. 2). Their photosynthesis was studied by analysing correlations with the fluorescence parameters according to the cultivation stages and in association with the differences in the treatments (Fig. 4). Earlier cultivation stage at days 2 and 4, the photosynthesis activities under all treatments were characterized by the parameters, $\mathrm{ET}_{0} / \mathrm{RC}$ and $\mathrm{F}_{\mathrm{V}} / \mathrm{F}_{0}$ (Fig. 4). $\mathrm{ET}_{0} / \mathrm{RC}$ estimates electron transport flux beyond the primary electron acceptor of PSII, the plastoquinone $\mathrm{Q}_{\mathrm{A}}$ (Strasser et al. 2000). $F_{V} / F_{0}$ is proportional to the activity of the water-splitting complex (Kalaji et al. 2011). The correlation with these parameters indicated steady operations of the PSII reaction centre (RC) and the electron transport activities. The photosynthesis under the bicarbonate treatment from day 6 to 14 was related to $F_{m}$ (Fig. 4). The parameter $F_{m}$ is equivalent to the peak $(\mathrm{P})$ of the OJIP transient curve, expressing a maximum of the fluorescence yield (Strasser et al. 2000, 2004; Cosgrove and Borowitzka 2010). $\mathrm{F}_{\mathrm{m}}$ characterized also the photosynthesis under the $\mathrm{CO}_{2}$ treatment at day 6 . However, the activities at days 8 and 14 were related rather to $\mathrm{DI}_{0} / \mathrm{RC}$ (Fig. 4), which 
Fig. 1 (a) Growth curves based on the optical density $(740 \mathrm{~nm})$ and (b) final biomass content (dry weight, $\mathrm{mg} \mathrm{L}^{-1}$ ) in the batch cultivation of $T$. wisconsinensis under different inorganic carbon regimes. No IC, aeration only; $\mathrm{HCO}_{3}{ }^{-}$, addition of $\mathrm{NaHCO}_{3}(20$ $\mathrm{mM})$ at the start of the experiment; $\mathrm{CO}_{2}$, continuous supply of $5 \% \mathrm{v} / \mathrm{v} \mathrm{CO}_{2}$ in air; and mixed, addition of $\mathrm{NaHCO}_{3}(20$ $\mathrm{mM})$ at the start and continuous supply of $5 \% \mathrm{v} / \mathrm{v} \mathrm{CO}_{2}$ in air. Error bars represent $\pm 1 \mathrm{SD}$ ( 3 cultivations for No IC, 2 cultivations for $\mathrm{HCO}_{3}{ }^{-}, \mathrm{CO}_{2}$, and mixed, 1 measurement from each)
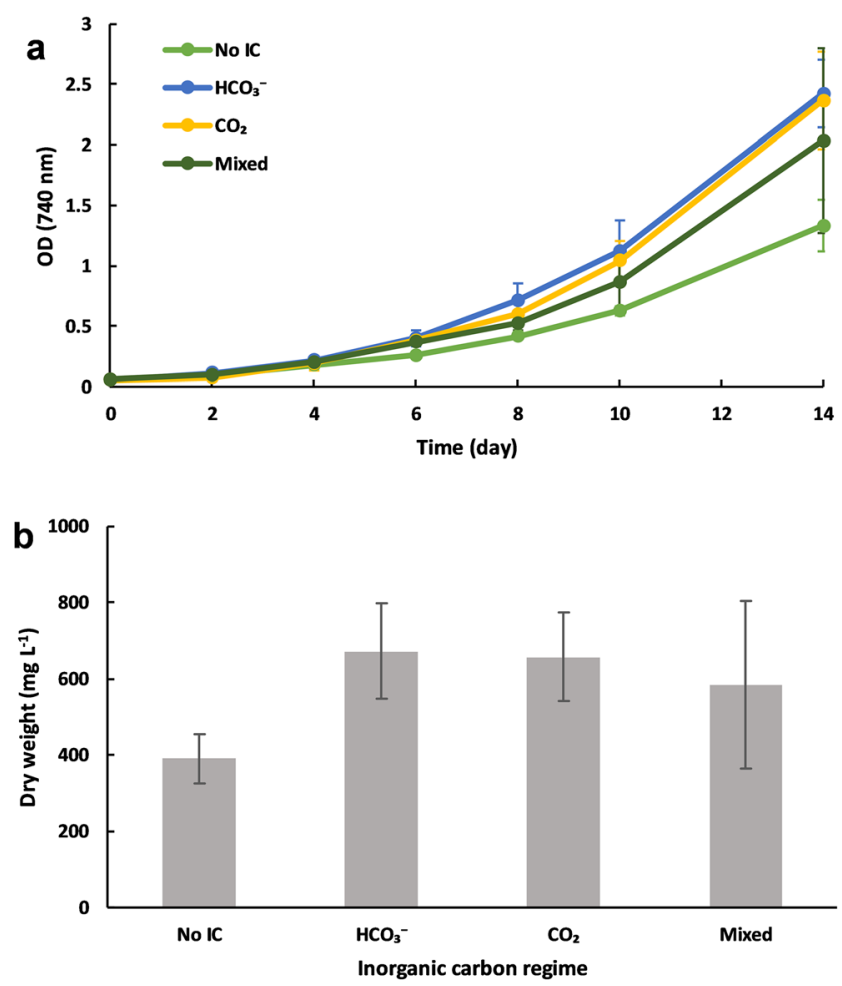

implied a high energy dissipation in the PSII operation (Strasser et al. 2000, 2004). Under the mixed carbon supplementation at days 6 and 8 , their photosynthesis was characterized by $F_{0}$ and $\mathrm{DI}_{0} / \mathrm{RC}$, respectively (Fig. 4). At day 14, their photosynthesis was no longer related to these parameters (Fig. 4).

Further, the efficiency of the PSII unit operations was compared by examining the changes of the maximum quantum yields of PSII $\left(\varphi_{\text {Po }}=F_{V} / F_{m}\right)$, the probability of trapped excitation energy moving into the electron transport chain $\left(\psi_{0}\right)$ (Strasser et al. 2004), and the absorption flux per active PSII RC (ABS/RC) (Strasser et al. 2004) under the different inorganic carbon regimes. The $\varphi_{\text {Po }}$ under the $\mathrm{CO}_{2}$ supplementation reduced noticeably at the later cultivation phase (Fig. 5a). At day 14, it decreased to $0.31( \pm 0.11)$, which was $55 \%$ reduction from the value shown at its peak at day 2 . In comparison, the $\varphi_{\text {Po }}$ under the bicarbonate supplementation at this stage was $0.57( \pm 0.10)$, which was only $26 \%$ reduction from the peak. Also, the $\psi_{0}$ under the $\mathrm{CO}_{2}$ supplementation showed a distinct reduction over time, although it was the highest of all at day 2 (Fig. 5b). The $\psi_{0}$ under the bicarbonate supplementation showed a marked increase from day 8 to 14 (Fig. $5 b$ ). The ABS/RC under the bicarbonate supplementation was stable, while these of the $\mathrm{CO}_{2}$ and mixed supplementation showed fluctuations (Fig. 5c). A constant increase of ABS/RC was particularly noticeable under the $\mathrm{CO}_{2}$ supplementation (Fig. 5c).

\section{Fatty acids}

The total fatty acids and the fatty acid profiles were similar between the inorganic carbon regimes (Fig. 6a and b). Total fatty acids measured at the end of the experiment varied between $65.7( \pm 2.3)$ under $\mathrm{CO}_{2}$-only treatment and $75.4( \pm 5.3)$
Table 1 Growth rates $\left(\right.$ day $\left.^{-1}\right)$ based on the optical density (at $740 \mathrm{~nm}$ ) measured in the batch cultivation of $T$. wisconsinensis under different inorganic carbon regime

\begin{tabular}{lllllll}
\hline & Day 0-2 & Day 2-4 & Day 4-6 & Day 6-8 & Day 8-10 & Day 10-14 \\
\hline $\mathrm{No} \mathrm{IC}^{-}$ & $0.27( \pm 0.01)$ & $0.31( \pm 0.03)$ & $0.18( \pm 0.01)$ & $0.24( \pm 0.02)$ & $0.20( \pm 0.03)$ & $0.19( \pm 0.03)$ \\
$\mathrm{HCO}_{3}$ & $0.31( \pm 0.08)$ & $0.33( \pm 0.06)$ & $0.30( \pm 0.10)$ & $0.29( \pm 0.01)$ & $0.22( \pm 0.02)$ & $0.20( \pm 0.01)$ \\
$\mathrm{CO}_{2}$ & $0.12( \pm 0.03)$ & $0.47( \pm 0.11)$ & $0.35( \pm 0.11)$ & $0.22( \pm 0.03)$ & $0.27( \pm 0.01)$ & $0.23( \pm 0.0004)$ \\
Mixed & $0.24( \pm 0.11)$ & $0.37( \pm 0.001)$ & $0.30( \pm 0.09)$ & $0.17( \pm 0.09)$ & $0.24( \pm 0.09)$ & $0.22( \pm 0.04)$ \\
\hline
\end{tabular}

No IC, no additional inorganic carbon source other than by aeration; $\mathrm{HCO}_{3}{ }^{-}$, addition of $20 \mathrm{mM} \mathrm{NaHCO}_{3}$ at the start of the experiment; $\mathrm{CO}_{2}$, continuous supply of $5 \% \mathrm{v} / \mathrm{v} \mathrm{CO}_{2}$ in air; and mixed, addition of $20 \mathrm{mM} \mathrm{NaHCO}_{3}$ at the start and continuous supply of $5 \% \mathrm{v} / \mathrm{v} \mathrm{CO}_{2}$ in air. Mean values ( \pm standard deviation) are given ( 3 cultivations for no IC, 2 cultivations for $\mathrm{HCO}^{-}, \mathrm{CO}_{2}$, and mixed, 3 measurements from each) 
Fig. 2 Concentrations of nitrogen and phosphorus in the growth media during batch cultivation of T. wisconsinensis. (a) Nitrate (mg $\mathrm{NO}_{3}{ }^{-} \mathrm{L}^{-1}$ ) and (b) phosphate ( $\mathrm{mg}$ $\left.\mathrm{PO}_{4}{ }^{3-} \mathrm{L}^{-1}\right)$. Error bars represent \pm $1 \mathrm{SD}$ ( 3 cultivations for no IC, 2 cultivations for $\mathrm{HCO}_{3}{ }^{-}, \mathrm{CO}_{2}$, and mixed, 1 measurement from each)
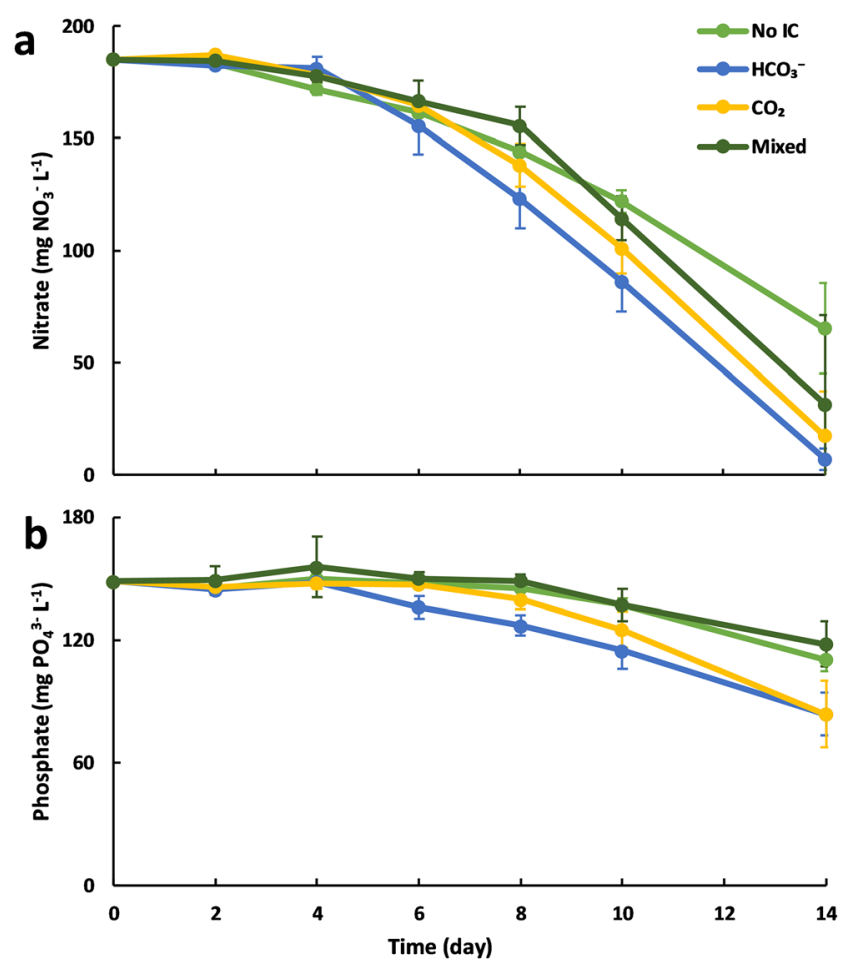

requirements for the maximum CFPP are country and season specific in the European standards EN 14214, and they vary between -26 and $+5^{\circ} \mathrm{C}$.

\section{Discussion}

\section{Growth, biomass production, and photosynthesis}

The results showed that bicarbonate was an effective inorganic carbon source for T. wisconsinensis. The bicarbonate regime supported a constant growth, which was indicated by the stable growth rate (Table 1). The final biomass yield in terms of dry cell weight was comparable to the $\mathrm{CO}_{2}$ regime (Fig. 1b). In addition, the bicarbonate-only supplementation supported efficient photosynthesis. The maximum quantum yield of PSII was relatively stable (Fig. 5a). Their photosynthesis activities are related to high activities of the electron transport flux $\left(\mathrm{ET}_{0} / \mathrm{RC}\right)$ and the water-splitting complex $\left(\mathrm{F}_{\mathrm{v}} /\right.$ $\mathrm{F}_{0}$ ) at the earlier cultivation stage. The increase in the maximum fluorescence $\left(\mathrm{F}_{\mathrm{m}}\right)$ at the late stage was assumed to be because of enhanced and unstressed photosynthesis activities. High intensity of maximum fluorescence was correlated with active growth in green microalgae, Chlorella vulgaris and Botryococcus braunii (Kula et al. 2017). On the other hand, Nannochloropsis sp. did not show a peak of the OJIP transient curve (i.e. $\mathrm{F}_{\mathrm{m}}$ ) after being exposed to a stress condition (Sukenik et al. 2009). Accordingly, we assumed that the photosynthesis under bicarbonate was driven by well-functioned, productive PSII. 


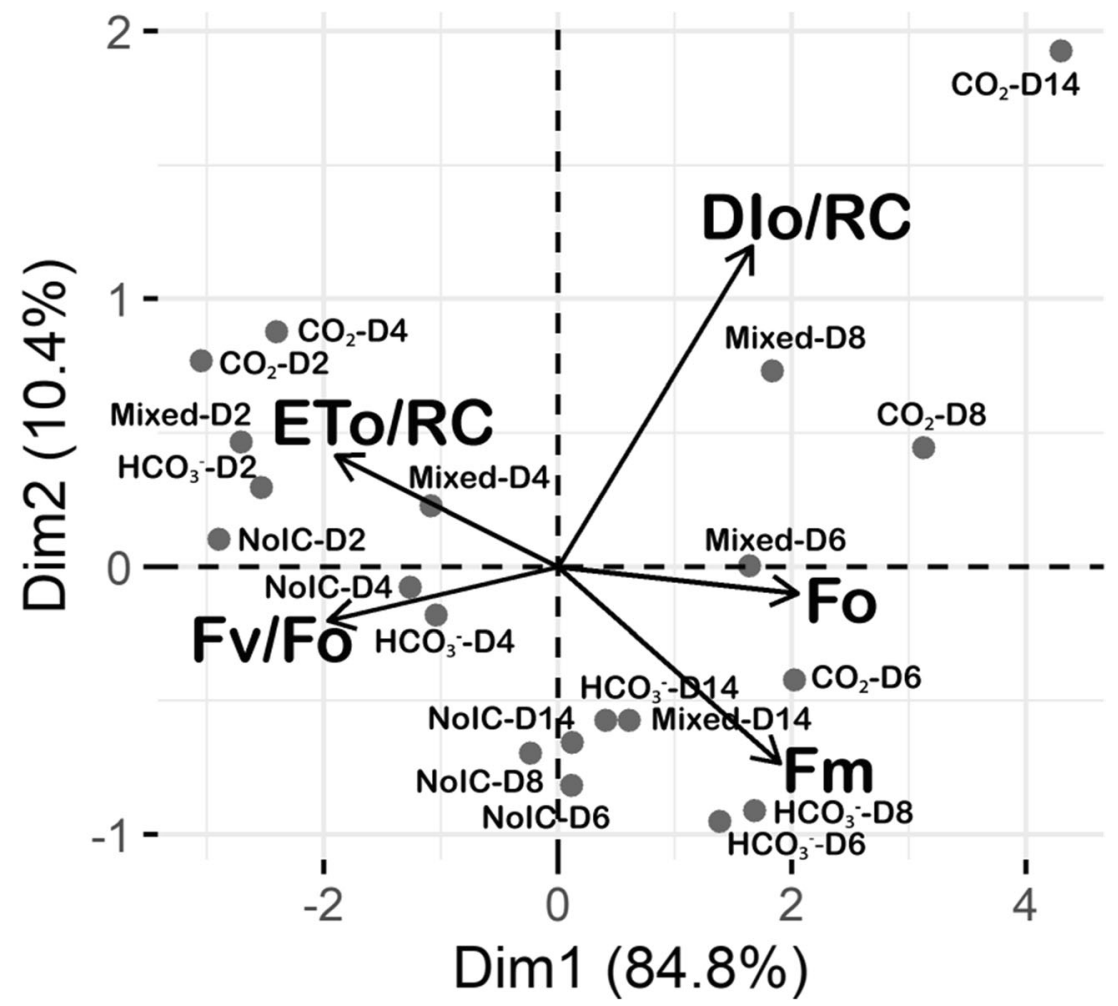

Fig. 4 Principal component analysis of selected photosynthesis parameters, $\mathrm{ET}_{0} / \mathrm{RC}, \mathrm{F}_{\mathrm{V}} / \mathrm{F}_{0}, \mathrm{DI}_{0} / \mathrm{RC}, \mathrm{F}_{\mathrm{m}}$, and $\mathrm{F}_{0}$, characterizing the PSII activities (Online Resource Table S1) of Tetradesmus wisconsisnensis grown under $70 \mu \mathrm{mol}$ photons $\mathrm{m}^{-2} \mathrm{~s}^{-1}$ with different regimes of inorganic carbon supplementation. The analysis was based on the chlorophyll $a$ fluorescence and JIP parameters measured at days (D) 2, $4,6,8$, and 14 during this study. The fluorescence parameters are shown

Despite the similarity in the final biomass yields between the bicarbonate and $\mathrm{CO}_{2}$ regimes, notable differences in growth rate and photosynthetic performance over the cultivation stages were found. The highest growth rate was recorded under the $\mathrm{CO}_{2}$-only regime. However, this regime resulted in a prolonged lag phase, which could be assumed by the low growth rate compared with the rates recorded for other regimes. At the later stage, photosynthesis under the $\mathrm{CO}_{2}$ regime showed inefficiency. Their photosynthesis activities were associated with $\mathrm{DI}_{0} / \mathrm{RC}$ (Fig. 4) and $\mathrm{ABS} / \mathrm{RC}$ and $\psi_{0}$ were considerably changed (Fig. $5 \mathrm{~b}$ and c). The results shown by these JIP parameters implied a reduction of operative PSII RCs, wasteful excitation energy within the PSII antenna complexes, and an overload of the electron transport between the donor side of PSII and the electron transport chain. The inefficiency of the PSII unit operation at this stage could also be confirmed by the substantially low quantum yield of primary photochemistry (Fig. 5a). In general, $\varphi_{\text {Po }}$ varies significantly by physiological conditions, and a range between 0.65 and 0.80 is suggested for non-stressed green microalgae (Masojídek et al. 2004). The lowering of $\varphi_{\mathrm{Po}}$ is an indication of inactivation of PSII by damages caused by environmental stress (Malapascua et al. 2014), or of sustained non- by arrows, and mean values of individual samples under the different regimes are shown as circles with labels showing regime hyphen(-) day. Their contributions, $\cos 2$ values, are listed in Online Resource Table S2. No IC, aeration only; $\mathrm{HCO}_{3}{ }^{-}$, addition of $\mathrm{NaHCO}_{3}(20 \mathrm{mM})$ at the start of the experiment; $\mathrm{CO}_{2}$, continuous supply $5 \% \mathrm{v} / \mathrm{v} \mathrm{CO}_{2}$ in air; and mixed, addition of $\mathrm{NaHCO}_{3}(20 \mathrm{mM})$ at the start and continuous supply of $5 \% \mathrm{v} /$ $\mathrm{v} \mathrm{CO}_{2}$ in air

photochemical quenching, i.e. dissipation of chlorophyll excitation energy as heat (Demmig-Adams and Adams 2006; Murchie and Lawson 2013).

The growth was not likely to be limited by the supply of phosphorus, and it was assumed to be limited by the nitrogen availability irrespective of inorganic carbon regimes (Fig. 2a and $b$ ). The differences in the growth and photosynthesis might be explained by the $\mathrm{pH}$ of the media. The medium under the $\mathrm{CO}_{2}$ regime reduced the $\mathrm{pH}$ to 5.2 at the initial stage, and this could cause the low growth rate. Moheimani (2013) reported that Chlorella sp. showed significantly lowered growth rate, biomass yield, and physiological change when they were grown at $\mathrm{pH} 5$, in contrast to other $\mathrm{pH}$ conditions above 5.5. The $\mathrm{pH}$ increase observed at day 14 under the $\mathrm{CO}_{2}$ regime might influence the photosynthesis activities. Accessibility of inorganic carbons to microalgae depends highly on $\mathrm{pH}$, because speciation of dissolved inorganic carbon in water is primarily determined by the $\mathrm{pH}$. The equilibrium point (pK) between $\mathrm{CO}_{2}$ and $\mathrm{HCO}_{3}{ }^{-}$is $\mathrm{pH} 6.3$ and this between $\mathrm{HCO}_{3}{ }^{-}$and $\mathrm{CO}_{3}{ }^{2-}$ is $\mathrm{pH} 10.3$ (Goldberg et al. 2003). The $\mathrm{pH}$ of the $\mathrm{CO}_{2}$-supplemented medium increased above the equilibrium point at day 14 ; therefore, a considerable change in the ratio of $\mathrm{CO}_{2}$ and $\mathrm{HCO}_{3}{ }^{-}$could be expected at this stage. 
Fig. 5 (a) Maximum quantum yields of PSII $\left(\varphi_{\mathrm{Po}}\right)$, (b) the probability of trapped excitation energy moving into the electron transport chain $\left(\psi_{0}\right)$, and $(\mathbf{c})$ the absorption of photons per active PSII reaction centre (ABS/RC) $\mathrm{m}^{-2} \mathrm{~s}^{-1}$ with different regimes of inorganic carbon additional inorganic carbon $\mathrm{HCO}_{3}{ }^{-}$, addition of $\mathrm{NaHCO}_{3}(20$ $\mathrm{mM}$ ) at the start of the experiment; $\mathrm{CO}_{2}$, continuous supply of $5 \% \mathrm{v} / \mathrm{v} \mathrm{CO}_{2}$ in air; and mixed, addition of $\mathrm{NaHCO}_{3}(20$ $\mathrm{mM})$ at the start and continuous bars represent \pm 1 SD ( 3 cultivations for no IC, 2 cultivations for $\mathrm{HCO}_{3}{ }^{-}, \mathrm{CO}_{2}$, and mixed, 1 measurement from each) grown under $70 \mu \mathrm{mol}$ photons

supplementation. NO IC, no source other than by aeration; supply of $5 \% \mathrm{v} / \mathrm{v} \mathrm{CO}_{2}$ in air. Error
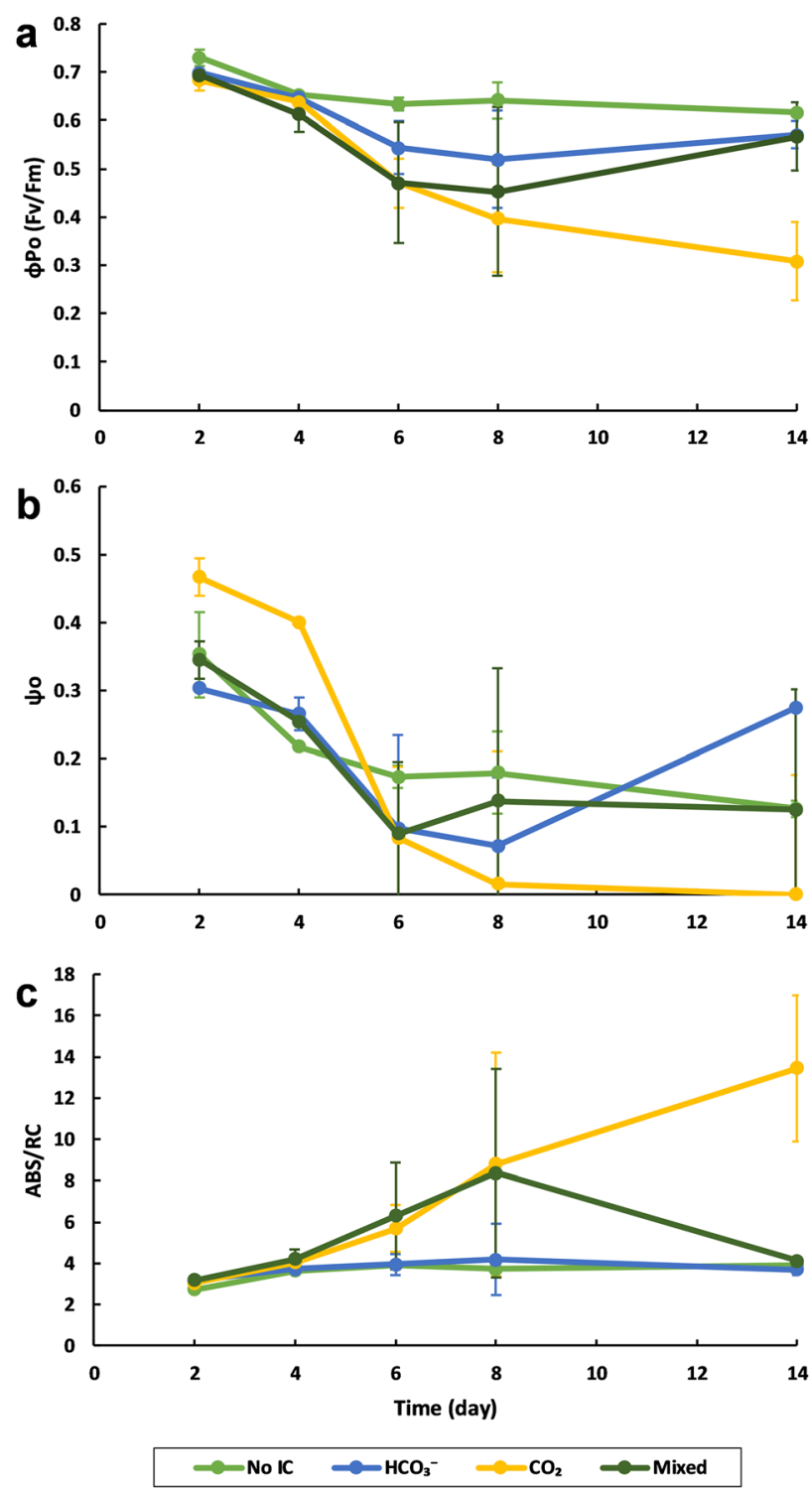

This change might cause a stress, which led to the reduction of photosynthetic efficiency. While $\mathrm{CO}_{2}$ is diffusive to cell membrane, intake of $\mathrm{HCO}_{3}{ }^{-}$requires an energy demanding process of CCM for microalgae (Moheimani and Borowitzka 2011). The $\mathrm{pH}$ recorded for the bicarbonate supplemented medium was from 7.9 to 10.1 ; hence, the available inorganic carbon species were mostly $\mathrm{HCO}_{3}{ }^{-}$and partly $\mathrm{CO}_{3}{ }^{2-}$. Nevertheless, no indication of adverse effect on growth or photosynthesis was observed. Interestingly, a lowered growth rate was recorded for the mixed carbon regime at day 8 (Table 1) when a marked increase of $\mathrm{pH}$ was observed (Fig. 3). Besides, a reduced photosynthetic performance was indicated at this stage (Figs 4). The following days (from day 10), however, the growth and photosynthesis seemed to be regained (Table 1 and Fig. 5a and c). The result might suggest that the organisms needed to acclimate to utilize $\mathrm{HCO}_{3}^{-}$when the $\mathrm{pH}$ raise reduced availability of $\mathrm{CO}_{2}$. CCMs in microalgae are known to be downregulated by the increasing concentration of $\mathrm{CO}_{2}$ gas (Beardall and Giordano 2002). Regulation of $\mathrm{pH}$ is important for optimal growth, photosynthesis, and lipid productivity in microalgae (Moheimani and Borowitzka 2011; Moheimani 2013), and stabilizing the $\mathrm{pH}$ is crucial when considering a scale-up operation with recycling of the medium (Borowitzka 2016). Further investigation on inorganic carbon uptake of $T$. wisconsinensis under mixed supplementation of bicarbonate and gaseous $\mathrm{CO}_{2}$ is required.

\section{Fatty acid production}

The total fatty acid production and the fatty acid profiles were similar regardless of the variations in inorganic carbon supplementation. Previous studies have shown enhanced accumulation of fatty acids in bicarbonate grown cells in comparison with atmospheric air or $\mathrm{CO}_{2}(5 \% \mathrm{v} / \mathrm{v})$ in green 
Fig. 6 Fatty acids measured in T. wisconsinensis $\mathrm{H} 1$ grown under four different inorganic carbon regimes. (a) Total fatty acids ( $\mathrm{mg} \mathrm{g}^{-1}$ dry biomass) and (b) fatty acid components $\left(\mathrm{mg} \mathrm{g}^{-1}\right.$ dry biomass). Error bars represent $\pm 1 \mathrm{SD}$ ( 3 cultivations for no IC, 2 cultivations for $\mathrm{HCO}_{3}{ }^{-}, \mathrm{CO}_{2}$, and mixed, 3 measurements from each) a
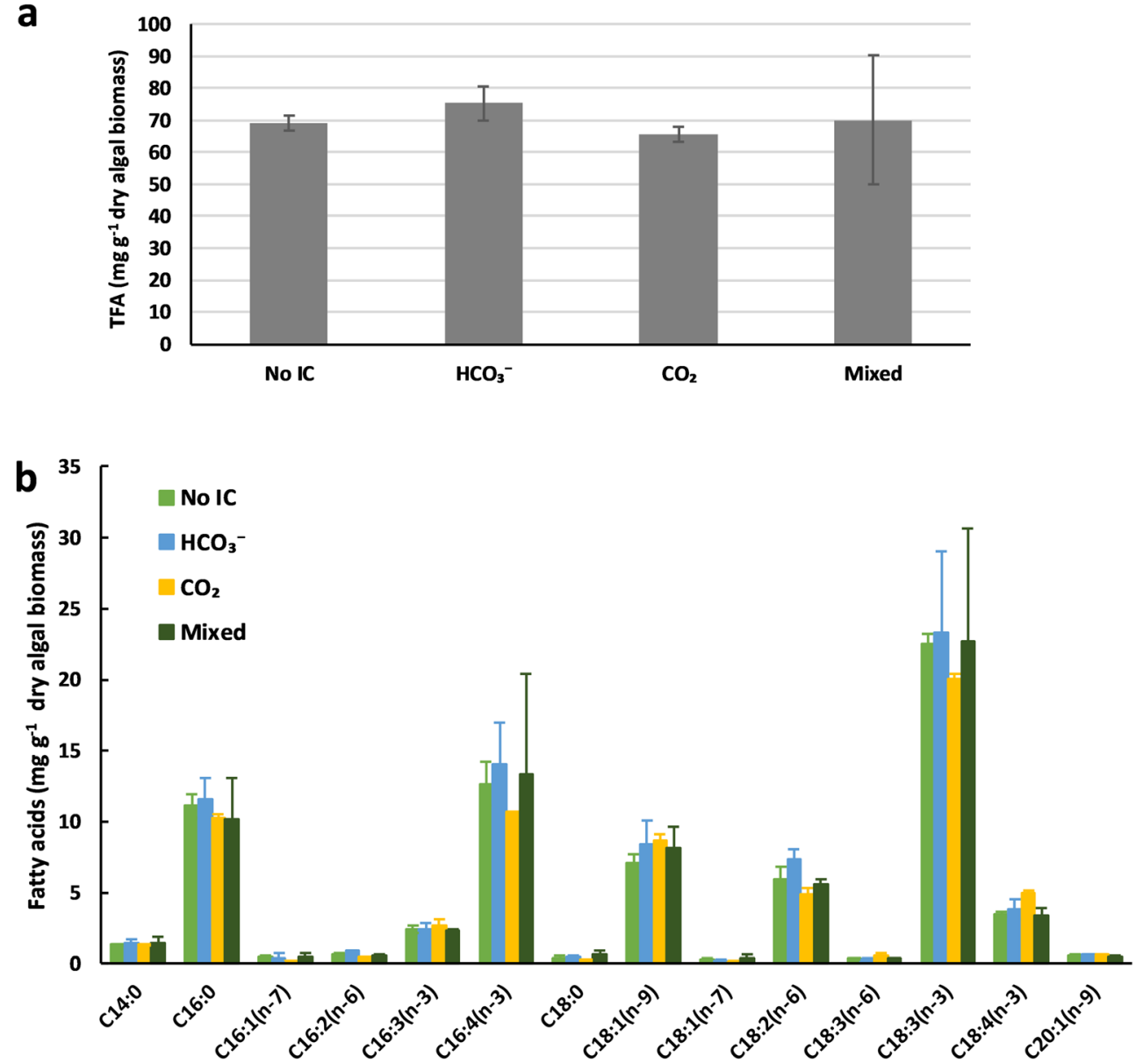

microalgae, Chlamydomonas reinhardtii (Gardner et al. 2013), Scenedesmus sp. (Gardner et al. 2012), and Chlorella vulgaris (Lohman et al. 2015). In these studies, much higher concentration $(50 \mathrm{mM})$ of $\mathrm{NaHCO}_{3}$ was supplied in addition to $\mathrm{CO}_{2}$ sparging, although they observed arrests of cellular replication after adding $\mathrm{NaHCO}_{3}($ Gardner et al. 2012,
Table 2 Biodiesel fuel properties calculated for the fatty acid profile of $T$. wisconsinensis

\begin{tabular}{llllll}
\hline Biodiesel properties & \multicolumn{2}{l}{ Inorganic carbon regime } & Total average \\
\cline { 2 - 5 } & NO IC & $\mathrm{HCO}_{3}{ }^{-}$ & $\mathrm{CO}_{2}$ & Mixed & \\
\hline SFA (\%) & $18.6( \pm 1.0)$ & $17.9( \pm 0.2)$ & $18.0( \pm 0.2)$ & $17.7( \pm 0.6)$ & $18.1( \pm 0.7)$ \\
MUFA (\%) & $12.1( \pm 0.8)$ & $13.1( \pm 3.7)$ & $14.6( \pm 0.3)$ & $13.8( \pm 2.6)$ & $13.3( \pm 1.9)$ \\
PUFA (\%) & $69.4( \pm 1.6)$ & $69.0( \pm 3.9)$ & $67.3( \pm 0.1)$ & $68.5( \pm 3.2)$ & $68.6( \pm 2.1)$ \\
$\mathrm{SV}\left(\mathrm{mg} \mathrm{KOH} \mathrm{g}^{-1}\right)$ & $199.6( \pm 0.3)$ & $199.4( \pm 0.4)$ & $199.1( \pm 0.1)$ & $199.3( \pm 0.9)$ & $199.4( \pm 0.3)$ \\
$\mathrm{IV}\left(\mathrm{g} \mathrm{I}_{2}\left(100 \mathrm{~g}^{-1}\right)\right.$ & $212( \pm 7)$ & $211( \pm 9)$ & $210( \pm 1)$ & $211( \pm 13)$ & $211( \pm 7)$ \\
$\mathrm{CN}$ & $26.0( \pm 1.6)$ & $26.2( \pm 2.1)$ & $26.5( \pm 0.2)$ & $26.2( \pm 3.1)$ & $26.2( \pm 1.6)$ \\
$\mathrm{DU}$ & $151( \pm 3)$ & $151( \pm 4)$ & $149( \pm 0.1)$ & $151( \pm 4)$ & $151( \pm 2)$ \\
$\mathrm{LCSF}$ & $1.9( \pm 0.2)$ & $1.9( \pm 0.002)$ & $1.8( \pm 0.02)$ & $2.0( \pm 0.3)$ & $1.9( \pm 0.2)$ \\
$\mathrm{CFPP}\left({ }^{\circ} \mathrm{C}\right)$ & $-10.5( \pm 0.5)$ & $-10.7( \pm 0.01)$ & $-10.9( \pm 0.1)$ & $-10.2( \pm 1.0)$ & $-10.6( \pm 0.5)$ \\
\hline
\end{tabular}

No IC, no additional inorganic carbon source other than by aeration; $\mathrm{HCO}_{3}{ }^{-}$, addition of $20 \mathrm{mM} \mathrm{NaHCO}_{3}$ at the start of the experiment; $\mathrm{CO}_{2}$, continuous supply of $5 \% \mathrm{v} / \mathrm{v} \mathrm{CO}_{2}$ in air; and mixed, addition of $20 \mathrm{mM} \mathrm{NaHCO}_{3}$ at the start and continuous supply of $5 \% \mathrm{v} / \mathrm{v} \mathrm{CO}_{2}$ in air. SFA, MUFA, and PUFA: the sum of saturated, monounsaturated, and polyunsaturated fatty acids in total fatty acids (wt\%). SV: the saponification number. IV: the iodine value. CN: the cetane number. DU: the degree of unsaturation. LCSF: the long-chain saturation factor. CFPP: the cold filter plugging point. Mean values ( \pm standard deviation) are given ( 3 cultivations for no IC; 2 cultivations for $\mathrm{HCO}^{-}, \mathrm{CO}_{2}$, and mixed; 3 measurements from each) 
2013). Therefore, a further investigation to compare effects of inorganic carbon regimes with a wider range of concentrations is necessary.

\section{Evaluation of the fatty acid profile for biotechnology}

The fatty acids of $T$. wisconsinensis strain $\mathrm{H} 1$ showed a large DU similar to those of peanuts, rapeseeds, and cottonseeds (Nascimento et al. 2014). The average DU was higher than other microalgal species examined previously (Islam et al. 2013; Nascimento et al. 2013, 2014; Valdez-Ojeda et al. 2015). A DU value as low as 28 was reported for a member of Chlorophyta, Chlamydomonas sp. (Islam et al. 2013; Nascimento et al. 2014). In addition, the $\mathrm{CN}$ for $T$. wisconsinensis FAME was lower than previously reported values of other microalgal species and vegetables (Ramos et al. 2009; Islam et al. 2013; Nascimento et al. 2014; Valdez-Ojeda et al. 2015). CN is an important indicator for engine performance, and a diesel oil with high $\mathrm{CN}$ will be advantageous for its short ignition time (Ramos et al. 2009; Nascimento et al. 2013). The CFPP was the only biodiesel property that would fulfil the requirement for FAME in the European standards. Overall, the fatty acid profile of the lipid showed a low quality for biodiesel. We concluded that T. wisconsinensis strain $\mathrm{H} 1$ is not well suited for biodiesel production.

Nevertheless, the high content of PUFA in the T. wisconsinensis lipid can be advantageous in functional food and feed applications. The dominant component of T. wisconsinensis FAMEs was $\alpha$-linolenic acid (C18:3, $n-3)$ followed by hexadecatetraenoic acid (C16:4, $n$-3) and palmitic acid (C16:0) (Fig. 6a). Hence, the fatty acid profile of T. wisconsinensis can be characterized as rich in $n-3$ fatty acids. The importance of $\alpha$-linolenic acid has been recognized as the precursor of EPA and DHA synthesis (KhozinGoldberg et al. 2011; Finco et al. 2017). The abundant presence of hexadecatetraenoic acid has been rarely reported in microalgae, although it has been found in chlorophytes (Zhukova and Aizdaicher 1995; Lang et al. 2011; Řezanka et al. 2017). Currently, food and feed market provides the second highest value for microalgae-based products (Barsanti and Gualtieri 2018). Recent expansion of the food market for algae products is encouraging the global food industry to develop new products containing microalgae (Lafarga 2019). Moreover, the fish farming industry is facing a challenge to improve the current feed formulation based on terrestrial plants, which is likely to give undesirably low $n-3 /$ $n-6$ fatty acid ratios in the fish products (Tibbetts et al. 2020). A recent study has shown a potential of $n$-3 PUFA-rich microalgae, Pavlova sp. 459, to be an alternative ingredient to salmonid feeds (Tibbetts et al. 2020). Therefore, the food and feed application will be a relevant direction for further research on the PUFA produced by our $T$. wisconsinensis strain.

\section{Conclusions}

In this paper we have shown a positive effect of bicarbonate supplementation on the photosynthesis of $T$. wisconsinensis, although there was no clear advantage over the productivity. On the contrary, some inefficiency was observed under the $\mathrm{CO}_{2}$ supplementation, and reduced photosynthetic performance was revealed particularly by the low quantum yield of PSII. Biomass yield, growth rates, and fatty acid production were similar regardless of the inorganic carbon regimes. The highest total fatty acid content was $75.4( \pm 5.3) \mathrm{mg} \mathrm{g}^{-1}$ dry algae biomass, and the fatty acid profile was characterized by an abundance of $\alpha$-linolenic acid (C18:3, $n$-3). The potential to use our strain as a source of biodiesel was constrained by high PUFA content, which presumed to give susceptibility for oxidation and low cetane number. Their $n$ - 3 PUFAs should be evaluated to see if they hold promise in functional food and/or animal feed production. From our findings, we confirmed that bicarbonate can be an effective inorganic carbon source that gives similar product yields as $\mathrm{CO}_{2}$. Bicarbonate would be a suitable alternation to $\mathrm{CO}_{2}$ sparging in microalgae culture. Further investigation is required to optimize $\mathrm{pH}$ of bicarbonate-supplemented medium, especially when bicarbonate is used as a partial substitution of gaseous $\mathrm{CO}_{2}$.

Supplementary Information The online version contains supplementary material available at https://doi.org/10.1007/s10811-021-02420-4.

Acknowledgements Open access funding provided by University of South-Eastern Norway. The authors would like to acknowledge Carlos Dinamarca, Frode Bergan, Hildegunn Hegna Haugen, and Karin Brekke Li for technical support and discussions of the experiment. The authors also thank Carl Ivar Holmen for providing gas regulators and technical consultation.

Authors' contributions The conception and design of study were developed by IU, EJ, SK, and RB. IU, EJ, MS, and CJH contributed to the data acquisition, analyses, and interpretation. IU wrote the manuscript with input from all authors. The final manuscript was approved by all authors.

Funding This study was funded by the University of South-Eastern Norway.

\section{Declarations}

Conflict of interest The authors declare no conflict of interest.

Open Access This article is licensed under a Creative Commons Attribution 4.0 International License, which permits use, sharing, adaptation, distribution and reproduction in any medium or format, as long as you give appropriate credit to the original author(s) and the source, 
provide a link to the Creative Commons licence, and indicate if changes were made. The images or other third party material in this article are included in the article's Creative Commons licence, unless indicated otherwise in a credit line to the material. If material is not included in the article's Creative Commons licence and your intended use is not permitted by statutory regulation or exceeds the permitted use, you will need to obtain permission directly from the copyright holder. To view a copy of this licence, visit http://creativecommons.org/licenses/by/4.0/.

\section{References}

An SS, Friedl T, Hegewald E (1999) Phylogenetic relationships of Scenedesmus and Scenedesmus-like coccoid green algae as inferred from ITS-2 rDNA sequence comparisons. Plant Biol 1:418-428

Baker NR (2008) Chlorophyll fluorescence: a probe of photosynthesis in vivo. Annu Rev Plant Biol 59:89-113

Baker NR, Rosenqvist E (2004) Applications of chlorophyll fluorescence can improve crop production strategies: an examination of future possibilities. J Exp Bot 55:1607-1621

Barsanti L, Gualtieri P (2018) Is exploitation of microalgae economically and energetically sustainable? Algal Res 31:107-115

Beardall J, Giordano M (2002) Ecological implications of microalgal and cyanobacterial $\mathrm{CO}_{2}$ concentrating mechanisms, and their regulation. Funct Plant Biol 29:335-347

Borowitzka MA (2013) High-value products from microalgae - their development and commercialisation. J Appl Phycol 25:743-756

Borowitzka MA (2016) Algal physiology and large-scale outdoor cultures of microalgae. In: Borowitzka MA, Beardall J, Raven JA (eds) The Physiology of Microalgae. Springer, Cham, pp 601-652

Chen Y, Zhang L, Xu C, Vaidyanathan S (2016) Dissolved inorganic carbon speciation in aquatic environments and its application to monitor algal carbon uptake. Sci Total Environ 541:1282-1295

Chi Z, O'Fallon JV, Chen S (2011) Bicarbonate produced from carbon capture for algae culture. Trends Biotechnol 29:537-541

Cosgrove J, Borowitzka MA (2010) Chlorophyll fluorescence terminology: an introduction. In: Suggett D, Prášil O, Borowitzka MA (eds) Chlorophyll $a$ fluorescence in aquatic sciences: methods and applications. Springer, Dordrecht, pp 1-17

Demmig-Adams B, Adams WW 3rd (2006) Photoprotection in an ecological context: the remarkable complexity of thermal energy dissipation. New Phytol 172:11-21

Ferrigo D, Galla G, Sforza E, Morosinotto T, Barcaccia G, Berrini C (2015) Biochemical characterization and genetic identity of an oilrich Acutodesmus obliquus isolate. J Appl Phycol 27:149-161

Finco AMO, Mamani LDG, Carvalho JC, de Melo Pereira GV, ThomazSoccol V, Soccol CR (2017) Technological trends and market perspectives for production of microbial oils rich in omega-3. Crit Rev Biotechnol 37:656-671

Gardner RD, Cooksey KE, Mus F, Macur R, Moll K, Eustance E, Carlson RP, Gerlach R, Fields MW, Peyton BM (2012) Use of sodium bicarbonate to stimulate triacylglycerol accumulation in the chlorophyte Scenedesmus sp and the diatom Phaeodactylum tricornutum. J Appl Phycol 24:1311-1320

Gardner RD, Lohman E, Gerlach R, Cooksey KE, Peyton BM (2013) Comparison of $\mathrm{CO}_{2}$ and bicarbonate as inorganic carbon sources for triacylglycerol and starch accumulation in Chlamydomonas reinhardtii. Biotechnol Bioeng 110:87-96

Georgianna DR, Mayfield SP (2012) Exploiting diversity and synthetic biology for the production of algal biofuels. Nature 488:329-335

Giordano M, Beardall J, Raven JA (2005) $\mathrm{CO}_{2}$ concentrating mechanisms in algae: mechanisms, environmental modulation, and evolution. Annu Rev Plant Biol 56:99-131

Goldberg RN, Kishore N, Lennen RM (2003) Thermodynamic quantities for the ionization reactions of buffers in water. In: Lide DR (ed)
CRC Handbook of Chemistry and Physics, 84th edn. CRC Press, Boca Raton, pp 1193-1195

Gonçalves AL, Pires JCM, Simões M (2017) A review on the use of microalgal consortia for wastewater treatment. Algal Res 24:403-415

Hegewald E, Bock C, Krienitz L (2013) A phylogenetic study on Scenedesmaceae with the description of a new species of Pectinodesmus and the new genera Verrucodesmus and Chodatodesmus (Chlorophyta, Chlorophyceae). Fottea 13:149-164

Hoshina R (2014) DNA analyses of a private collection of microbial green algae contribute to a better understanding of microbial diversity. BMC Res Notes 7:592

Hoshina R, Kato Y, Kamako S, Imamura N (2005) Genetic evidence of "American" and "European" type symbiotic algae of Paramecium bursaria Ehrenberg. Plant Biol 7:526-532

Hu Q, Sommerfeld M, Jarvis E, Ghirardi M, Posewitz M, Seibert M, Darzins A (2008) Microalgal triacylglycerols as feedstocks for biofuel production: perspectives and advances. Plant J 54:621-639

Hulatt CJ, Wijffels RH, Bolla S, Kiron V (2017) Production of fatty acids and protein by Nannochloropsis in flat-plate photobioreactors. PLoS One 12:e170440

Islam M, Magnusson M, Brown R, Ayoko G, Nabi M, Heimann K (2013) Microalgal species selection for biodiesel production based on fuel properties derived from fatty acid profiles. Energies 6:5676-5702

Ismagulova T, Chekanov K, Gorelova O, Baulina O, Semenova L, Selyakh I, Chivkunova O, Lobakova E, Karpova O, Solovchenko A (2018) A new subarctic strain of Tetradesmus obliquus - part I: identification and fatty acid profiling. J Appl Phycol 30:2737-2750

Janka E, Umetani I, Sposob M, Bakke R (2019) Special issue in honour of Prof. Reto J. Strasser - Photosynthesis response of microalgae (Tetradesmus wisconsinensis) to different inorganic carbon sources probed with chlorophyll fluorescence analysis. Photosynthetica 57:51-59

Kalaji HM, Govindjee, Bosa K, Kościelniak J, Żuk-Gołaszewska K (2011) Effects of salt stress on photosystem II efficiency and $\mathrm{CO}_{2}$ assimilation of two Syrian barley landraces. Environ Exp Bot 73:64-72

Khozin-Goldberg I, Iskandarov U, Cohen Z (2011) LC-PUFA from photosynthetic microalgae: occurrence, biosynthesis, and prospects in biotechnology. Appl Microbiol Biotechnol 91:905-915

Krisnangkura K (1986) A simple method for estimation of cetane index of vegetable oil methyl esters. J Am Oil Chem Soc 63:552-553

Kula M, Kalaji HM, Skoczowski A (2017) Culture density influence on the photosynthetic efficiency of microalgae growing under different spectral compositions of light. J Photochem Photobiol B 167:290298

Lafarga T (2019) Effect of microalgal biomass incorporation into foods: Nutritional and sensorial attributes of the end products. Algal Res 41:101566

Lang I, Hodac L, Friedl T, Feussner I (2011) Fatty acid profiles and their distribution patterns in microalgae: a comprehensive analysis of more than 2000 strains from the SAG culture collection. BMC Plant Biol 11:124

Lazar D (1999) Chlorophyll $a$ fluorescence induction. Biochim Biophys Acta-Bioenergetics 1412:1-28

Lê S, Josse J, Husson F (2008) FactoMineR: an R package for multivariate analysis. J Stat Softw 25:18

Lohman EJ, Gardner RD, Pedersen T, Peyton BM, Cooksey KE, Gerlach R (2015) Optimized inorganic carbon regime for enhanced growth and lipid accumulation in Chlorella vulgaris. Biotechnol Biofuels 8:82

Malapascua JRF, Jerez CG, Sergejevová M, Figueroa FL, Masojídek J (2014) Photosynthesis monitoring to optimize growth of microalgal mass cultures: application of chlorophyll fluorescence techniques. Aquat Biol 22:123-140

Masojídek J, Koblížek M, Torzillo G (2004) Photosynthesis in microalgae. In: Richmond A (ed) Handbook of microalgal culture: Biotechnology and applied phycology. Blackwell, Oxford, pp 20 39 
Maxwell K, Johnson GN (2000) Chlorophyll fluorescence-a practical guide. J Exp Bot 51:659-668

Mayers JJ, Flynn KJ, Shields RJ (2014) Influence of the N:P supply ratio on biomass productivity and time-resolved changes in elemental and bulk biochemical composition of Nannochloropsis sp. Bioresour Technol 169:588-595

Meier L, Perez R, Azocar L, Rivas M, Jeison D (2015) Photosynthetic $\mathrm{CO}_{2}$ uptake by microalgae: an attractive tool for biogas upgrading. Biomass Bioenergy 73:102-109

Moheimani NR (2013) Inorganic carbon and $\mathrm{pH}$ effect on growth and lipid productivity of Tetraselmis suecica and Chlorella $\mathrm{sp}$ (Chlorophyta) grown outdoors in bag photobioreactors. J Appl Phycol 25:387-398

Moheimani NR, Borowitzka MA (2011) Increased $\mathrm{CO}_{2}$ and the effect of $\mathrm{pH}$ on growth and calcification of Pleurochrysis carterae and Emiliania huxleyi (Haptophyta) in semicontinuous cultures. Appl Microbiol Biotechnol 90:1399-1407

Mondal M, Goswami S, Ghosh A, Oinam G, Tiwari ON, Das P, Gayen K, Mandal MK, Halder GN (2017) Production of biodiesel from microalgae through biological carbon capture: a review. 3. Biotech 7:99

Murchie EH, Lawson T (2013) Chlorophyll fluorescence analysis: a guide to good practice and understanding some new applications. J Exp Bot 64:3983-3998

Nascimento IA, Marques SSI, Cabanelas ITD, Pereira SA, Druzian JI, de Souza CO, Vich DV, de Carvalho GC, Nascimento MA (2013) Screening microalgae strains for biodiesel production: lipid productivity and estimation of fuel quality based on fatty acids profiles as selective criteria. BioEnerg Res 6:1-13

Nascimento IA, Marques SSI, Cabanelas ITD, de Carvalho GC, Nascimento MA, de Souza CO, Druzian JI, Hussain J, Liao W (2014) Microalgae versus land crops as feedstock for biodiesel: productivity, quality, and standard compliance. Bioenerg Res 7: 1002-1013

Posada JA, Brentner LB, Ramirez A, Patel MK (2016) Conceptual design of sustainable integrated microalgae biorefineries: parametric analysis of energy use, greenhouse gas emissions and techno-economics. Algal Res 17:113-131

Ramos MJ, Fernandez CM, Casas A, Rodriguez L, Perez A (2009) Influence of fatty acid composition of raw materials on biodiesel properties. Bioresour Technol 100:261-268

Raven JA (2010) Inorganic carbon acquisition by eukaryotic algae: four current questions. Photosynth Res 106:123-134

Raven JA, Beardall J (2014) $\mathrm{CO}_{2}$ concentrating mechanisms and environmental change. Aquat Bot 118:24-37

Řezanka T, Nedbalová L, Lukavský J, Střížek A, Sigler K (2017) Pilot cultivation of the green alga Monoraphidium sp. producing a high content of polyunsaturated fatty acids in a low-temperature environment. Algal Res 22:160-165

Scherholz ML, Curtis WR (2013) Achieving pH control in microalgal cultures through fed-batch addition of stoichiometrically-balanced growth media. BMC Biotechnol 13:39

Singh J, Dhar DW (2019) Overview of carbon capture technology: microalgal biorefinery concept and state-of-the-art. Front Mar Sci 6:29

Slade R, Bauen A (2013) Micro-algae cultivation for biofuels: cost, energy balance, environmental impacts and future prospects. Biomass Bioenergy 53:29-38

Smith GM (1916) Tetradesmus, a new four-celled coenobic alga. Bull Torrey Bot Club 40:75-87

Sposob M, Bakke R, Dinamarca C (2017) Metabolic divergence in simultaneous biological removal of nitrate and sulfide for elemental sulfur production under temperature stress. Bioresour Technol 233: 209-215

Stirbet A, Govindjee (2011) On the relation between the Kautsky effect (chlorophyll $a$ fluorescence induction) and photosystem II: basics and applications of the OJIP fluorescence transient. J Photochem Photobiol B 104:236-257

Strasser RJ, Srivastava A, Govindjee (1995) Polyphasic chlorophyll $a$ fluorescence transient in plants and cyanobacteria. Photochem Photobiol 61:32-42

Strasser RJ, Srivastava A, Tsimilli-Michael M (2000) The fluorescence transient as a tool to characterize and screen photosynthetic samples. In: Yunus M, Pathre U, Mohanty P (eds) Probing Photosynthesis: Mechanisms. Regulation and Adaptation. Taylor and Francis, London, pp 445-483

Strasser RJ, Tsimilli-Michael M, Srivastava A (2004) Analysis of the chlorophyll $a$ fluorescence transient. In: Papageorgiou GC, Govindjee (eds) Chlorophyll $a$ fluorescence: A signature of photosynthesis. Springer, Dordrecht, pp 321-362

Sukenik A, Beardall J, Kromkamp J, Kopecký J, Masojídek J, Bergeijk SV, Gabai S, Shaham E, Yamshon A (2009) Photosynthetic performance of outdoor Nannochloropsis mass cultures under a wide range of environmental conditions. Aquat Microb Ecol 56:297-308

Thielmann J, Tolbert NE, Goyal A, Senger H (1990) Two systems for concentrating $\mathrm{CO}_{2}$ and bicarbonate during photosynthesis by Scenedesmus. Plant Physiol 92:622-629

Tibbetts SM, Patelakis SJJ, Whitney-Lalonde CG, Garrison LL, Wall CL, MacQuarrie SP (2020) Nutrient composition and protein quality of microalgae meals produced from the marine prymnesiophyte Pavlova sp. 459 mass-cultivated in enclosed photobioreactors for potential use in salmonid aquafeeds. J Appl Phycol 32:299-318

Valdez-Ojeda R, González-Muñoz M, Us-Vázquez R, Narváez-Zapata J, Chavarria-Hernandez JC, López-Adrián S, Barahona-Pérez F, Toledano-Thompson T, Garduño-Solórzano G, Escobedo-Gracia Medrano RM (2015) Characterization of five fresh water microalgae with potential for biodiesel production. Algal Res 7:33-44

Wang J, Curtis WR (2016) Proton stoichiometric imbalance during algae photosynthetic growth on various nitrogen sources: toward metabolic $\mathrm{pH}$ control. J Appl Phycol 28:43-52

Wells ML, Potin P, Craigie JS, Raven JA, Merchant SS, Helliwell KE, Smith AG, Camire ME, Brawley SH (2017) Algae as nutritional and functional food sources: revisiting our understanding. J Appl Phycol 29:949-982

White TJ, Bruns T, Lee S, Taylor J (1990) Amplification and direct sequencing of fungal ribosomal RNA genes for phylogenetics. In: Innis M, Gelfand D, Sninsky J, White T (eds) PCR protocols: a guide to methods and application. Academic Press, San Diego, pp 315-322

White DA, Pagarette A, Rooks P, Ali ST (2013) The effect of sodium bicarbonate supplementation on growth and biochemical composition of marine microalgae cultures. J Appl Phycol 25:153-165

Wynne MJ, Hallan JK (2015) Reinstatement of Tetradesmus G. M. Smith (Sphaeropleales, Chlorophyta). Feddes Repert 126:83-86

Zhukova NV, Aizdaicher NA (1995) Fatty acid composition of 15 species of marine microalgae. Phytochemistry 39:351-356

Baker NR, Oxborough K (2004) Chlorophyll fluorescence as a probe of photosynthetic productivity. In: Papageorgiou GC, Govindjee (eds) Chlorophyll $a$ fluorescence. A signature of photosynthesis. Springer, Dordrecht pp 65-82

Bischoff HW, Bold HC (1963) Phycological studies IV. Some soil algae from enchanted rock and related algal species. Phycological Studies, University of Texas IV:1-95

Wigmosta MS, Coleman AM, Skaggs RJ, Huesemann MH, Lane LJ (2011) National microalgae biofuel production potential and resource demand. Water Resour Res 47 (3)

Publisher's note Springer Nature remains neutral with regard to jurisdictional claims in published maps and institutional affiliations. 